\title{
What research for what training in psychotherapy? Some methodological issues and a proposal
}

\author{
Santo Di Nuovo \\ Department of Educational Sciences, Section of Psychology, University of Catania, Italy
}

\begin{abstract}
To define boundaries and links between research and training in psychotherapy we have to establish what kind of research is needed for this purpose. For defining psychotherapy as a science some basic epistemological premises should be affirmed and specific methods have to be devised, using both quantitative and qualitative approaches, diachronic and longitudinal perspectives, cumulative and meta-analytic strategies, focusing both the techniques used in the therapies and the relationship between the therapist subject and the client subject as a core mean for produce change. What should be evaluated in this research process, what methods and techniques of assessment should be preferred, what analyses of data are suitable: these are the main issues addressed in the article, as they are useful for planning the training of a therapist as a researcher, regardless of the privileged theoretical and technical approach. Science and practice have to be connected, since they both allow the monitoring of what occurs within the confines of the therapy and favor exchange among psychotherapists from differing theoretical approaches, which also increases their external visibility in the scientific community and in a wider social context. The goal of fostering scientific attitudes in the psychotherapists needs a specific training, to acquire a research mindedness also out of the academic laboratories. A cooperation among scientific associations and institutions is proposed to reach these objectives necessary for psychotherapists' trainings including competencies in evaluating and sharing the scientific aspects of their work.
\end{abstract}

Key words: Psychotherapy research; Psychotherapy training; assessment; single-case studies.

\section{Introduction}

\section{Is psychotherapy a science?}

In general, knowledge is recognized as scientific when it can be intersubjectively tested and communicated. Psy-

Correspondence: Santo Di Nuovo, Department of Educational Sciences, Section of Psychology, University of Catania, Palazzo Ingrassia, via Biblioteca 4, Catania 95124, Italy.

E-mail: s.dinuovo@unict.it

Citation: Di Nuovo, S. (2019). What research for what training in psychotherapy? Some methodological issues and a proposal. Research in Psychotherapy: Psychopathology, Process and Outcome, 22(3), 326-332. doi: 10.4081/ripppo.2019.410

Conflict of interest: the author declares no potential conflict of interest.

Funding: none

Received for publication: 28 June 2019

Revision received: 10 October 2019

Accepted for publication: 11 October 2019.

This work is licensed under a Creative Commons Attribution NonCommercial 4.0 License (CC BY-NC 4.0).

${ }^{\circ}$ Copyright: the Author(s), 2019

Licensee PAGEPress, Italy

Research in Psychotherapy:

Psychopathology, Process and Outcome 2019; 22:326-332

doi:10.4081/ripppo.2019.410 chotherapy can respond to the requirements for a scientific discipline if it gives clear definitions of concepts and postulates, plans interpretable and repeatable procedures, uses a rationally grounded method for the validation of hypotheses.

Psychotherapy as a science should consequently be based on some main epistemological assumptions: each therapeutic process has specific goals deriving from the theoretical model adopted by the therapist and from a preliminary assessment based on specific psychological criteria; the change is produced using techniques coherent with the theoretical model (the most suitable and economical in view of the conditions of the client and the context) and applied within a relation between two subjects: the therapist and the client (may be an individual, or a family, or a group); these aspects can be evaluated and explained in empirical studies, with methodological criteria shared in the scientific community to ensure intersubjectivity of control.

An important contribution to the affirmation of psychotherapy as a science derives from recent developments of neurosciences, overcoming a reductionist approach in search of unequivocal brain locations or clear genetic alterations, which has given contradictory and inconclusive results (Kandel, Schwartz, Jessell, Siegelbaum, \& Hudspeth, 2013, part IX). On the other hand, neuroscientific evidences demonstrate that both pharmacological and psychological interventions are aimed at modifying biological aspects: neurobiological and psychological effects are not dualistically distinct aspects but they pick up, each 
for its own part, facets of the same reality (Gabbard, 2009, chapter 29). Consequently, the psycho-biological alterations related to psychic pathologies can be addressed from different sides: exclusively biological (e.g., transcranial magnetic stimulations, psychotropic drugs), entirely psychological (using verbal mediation), or integrating the two approaches. The association between biological interventions and psychological techniques - where this synergy is indicated and useful - appears the best way to obtain more effective and lasting benefits. This is not surprising, as the biological substrate of the mind supports knowledge, emotions and behaviors, and therefore varies according to the changes in these aspects. Furthermore, neuronal plasticity and epigenetic variations allow for the possibility of restructuring the biological system that psychotherapy can activate, like drugs and indeed with more long-term effects. Le Doux (2000) concluded that psychotherapy is both a learning process for patients, and a way of changing the structure of brain connections. In this sense, psychotherapy basically uses biological mechanisms to treat mental illnesses, allowing the brain to change itself (Doidge, 2007).

The need for integration between psychobiological and psychotherapeutic intervention, clearly affirmed after decades of research on the effectiveness of psychotherapies, should be the basis for a scientific understanding of how psychotherapy actually works (Wampold \& Imel, 2015); and, in turn, for the competent and updated training of psychotherapists prepared by post-graduate specialization schools.

\section{Psychotherapy that works: scientific criteria and methods}

To assess in terms of scientific psychology if and how well the therapy works, a nomothetic, quantitative approach is required with the aim of assessing to what degree the client's symptoms, perceptions, affects and wellbeing change after treatment; whether - on the basis of tests repeated and compared to the normative values the client can be deemed to have re-entered in the threshold of normality, or anyway whether the difference from the norm is significantly reduced than in the pre-test; whether these changes are maintained over time. This is the preferred approach to test the changes (also biological, as we have previously seen) resulting as effect of the therapeutic intervention. But an idiographic, qualitative approach is also needed to follow in detail the changing of the specific variables within the treatment, and to monitoring the psychological consequences that this transformation produces and maintains over time; moreover, to understand the meaning that the changes have in the daily life of the client.

In this parallel use of quantitative and qualitative evaluations, the criteria for scientific validation are different but convergent (Lutz \& Knox, 2013). The scientific as- sessment of the therapy has necessarily to take into account the criterion of overcoming - or significantly reducing - the problems that led the client to undertake it, or that emerged during the therapy (criterion of effectiveness, based on the evaluation of the outcomes). However, the unicity and unrepeatability of what happens during the therapy, and the search for the psychological meaning of the change, makes it necessary to use also process-based criteria of evaluation. The aspects of regularity and uniqueness may be combined as long as appropriate methodological tools are found for the rigorous study of the diachronic nature of the process of change, the tendencies found in them are monitored, and the sense of what happens in the psychotherapy can be reconstructed (Rennie, 2012).

As regards the methodological tools, quantitative instruments like psychometric tests or observation grids are aimed at obtaining scores calibrated on the specific typical populations to which the client belongs. But also qualitative techniques are needed to follow the process-based variables of the intervention (Gelo, Salcuni, \& Colli, 2012): schedules to be compiled by the client and/or by the therapist or external observer; reports or transcripts of what happens in therapy, of the verbalizations, of the non-verbal and relational components; techniques based on imagination, drawing, games and role-playing, particularly suitable for children and teenagers. The qualitative approach needs tools designed for the in-depth examination of the semantic elements occurring during the treatment and particularly pertaining to the relationship established between the therapist subject and the client subject; that is, the core of any psychotherapeutic approach (Price \& Jones, 1998). Many studies on this issue confirm that the therapeutic relationship can be the object of empirical research, studying its correlations with other both process and outcome variables (Ardito \& Rabellino, 2011; Flückiger, Del Re, Wampold, Symonds, \& Horvath, 2012; Hill \& Knox, 2009; Martin, Garske, \& Davis, 2000).

To study these qualitative features of the therapy it may be useful to collect information both along the treatment (using appropriate schedules and grids about client's and therapist's attitudes and feelings) and at its end, e.g. through an open interview focused on what happened during the treatment itself in the client's view, regarding variables such as the relationship with the therapist, the feeling of the therapy's effectiveness, the satisfaction of expectations, etc. (Elliott, 2000). At the same time, the report on the experience can also be elicited from the therapist so as to compare the two evaluations and bring out the overall meaning of the treatment before ending it.

\section{Can science and practice be connected?}

The traditional separation between who produces research and who applies its results, based on models of pharmacological and medical sciences, has been chal- 
lenged and partly set aside in the social sciences. As regards the applied fields of psychology, the necessity of associating research and intervention is widely shared, and in Italy the law which ordinates the psychological profession declares that both experimentation and research are typical duties for professionals in psychology. Both correct applications of techniques and methodologically grounded studies are necessary for progress of the therapy (Lane \& Corrie, 2006).

Therefore we need therapists able to integrate in their clinical work an action-research perspective aimed at monitoring and verifying the efficacy and efficiency of the treatment. Empirical results (e.g., Castonguay et al., 2010) have demonstrated that the effort required to integrate research protocol in clinical practice provides useful information for improving the clients-therapists relationships and enhancing the efficacy of the treatment itself. Moreover, the capacity of the psychotherapists, belonging to different theoretical approaches, of assuring scientific proofs of efficacy of their professional work, fosters both the exchanges with the scientific community and the possibility of validating the theoretical models in the social context. In psychotherapy the laboratory of research is the clinical setting, and in this (not artificial) setting scientific methods have to be applied to assure the reliability of the therapeutic process and outcomes.

\section{The scientific attitude of the psychotherapist: need for a specific training}

The results of research on psychotherapies drive the professional community to pay more attention to the quality of the training of therapists, based on integration of theoretical-epistemic and technical-methodological aspects. The training courses, and the supervision included in them, should increase competencies and skills of the learners to evaluate the clinical work and the achievement of the planned goals (Hill \& Knox, 2013). The willingness to monitor one's work and tolerate being observed and evaluated by external sources are fundamental aspects of therapeutic competence which favor the reduction of iatrogenic risks. This further enhances some traditional features of training, such as self-monitoring ability, since the variables related to the person of the therapist are central to the therapeutic process and its outcomes.

How to realize these principles in the training of psychotherapists? Firstly, transmitting the cumulated knowledge on psychotherapy research; adequate space is needed for this presentation during the specialization courses. Moreover, future psychotherapists should be trained to approach psychotherapy as research, providing the appropriate methodological skills and stimulating the interest in using them. Psychotherapists - primarily novices, but also the experienced ones - should acquire the scientific attitude assuming a phenomenological mind (Gallagher \& Zahavi, 2008), i.e., searching for what is specific and original in the case (or group, or couple, or family) treated, avoiding that pre-judicial schemas - although derived from theoretical knowledge of from previous successful treatments - can influence the present assessment and planning.

Another prejudice which should be overcome is the attitude - shared by many researchers and clinicians - regarding the kind of research needed in the evaluation of psychotherapy. The identification of the empirical approach with the experimental one (where independent variables can be manipulated by the researcher), the limitation of the techniques for collecting data to the quantitative ones, and the consequent inappropriateness of applying these criteria to the very complex and often stochastic psychotherapeutic process, can explain why the research is viewed with diffidence by many professionals. Therefore they should learn that empirical but non-experimental (e.g., observational) and qualitative (e.g., contentbased) methods can be used to study also the subjective and relational aspects typical of the psychotherapy.

An interesting example of the qualitative approach is the conversational method. Among the qualitative methods, this model (Hobson, 1985; Meares, 2004) integrates developmental psychology, linguistics, and neuroscience, with the main aim of detecting the trauma and integrating it into a coherent sense of self. The patient's self can develop in the flux of the conversation in the therapeutic setting, allowing and encouraging a relation called aloneness-togetherness (according to Winnicott's suggestion of being alone in the presence of another). The conversation is more than the simple transmission of information about its content. It manifests and constitutes not only a form of consciousness but also a form of relatedness...the form of relatedness is transformational (Meares, 2004, p. 51). Through the empathic listening and a common feeling language, the patients feel accepted and understood; their self (as a sense of personal being) is enhanced, dropping the defenses which disrupt it. The Conversational Model of Therapy, which is also known as Psychodynamic-Interpersonal Therapy, is an evidencebased psychological treatment, and it shares many common theoretical approaches with other psychodynamic models. (Guthrie \& Moorey, 2018, p. 282). Considering what the conversation produces in the treatment room allows finding useful guidelines for monitoring the therapeutic process. Studies based mainly on qualitative analyses have found the model effective for the treatment of Borderline Personality Disorder (Meares, 2012) and other forms of pathology (Korner \& McLean, 2017; Peräkylä, Antaki, Vehviläinen, \& Leudar, 2008).

The training of psychotherapists should include the methodological issues regarding the translation of the variables present during the treatment into qualitative indicators and the statistics useful for analyzing them, as reliable as the traditional ones.

Last, but not least, the complexity of the object of re- 
search (Getz \& Campo, 2017) can be treated by multivariate methods and/or through a cumulative strategy of analysis of results of single studies. The reductive approach typical of the randomized clinical trials (useful in medical and pharmacological fields) can be redeemed by methods useful for coping with complexity, now available and useful in clinical research (Kazdin, 2016). In this sense, the individual therapists can provide their data to research groups that collect and analyze the results cumulatively to bring new light on the efficacy and the sense of the psychotherapy model they practice.

\section{Some issues for training research in psychotherapy}

The program of methodological training of the psychotherapy specialists should include the answers to the fundamental questions of psychotherapy research, affirmed in several decades of empirical studies (e.g., Lambert, 2013). Some main issues have to be specifically addressed.

\section{Why evaluate}

The aim is to determine the outcome - even quantitative - of the treatment with respect to the clients' problems, but also to monitor the therapeutic process while it takes place. Efficacy and efficiency should be strictly joined in clinical psychology: the goal is to assess what works for whom (Norcross \& Wampold, 2011), for helping therapists to tailor the intervention to the specific client. This approach reflects a general, recently affirmed, paradigm in psychology centered on specific persons beyond the traditional studies based on groups (Molenaar \& Campbell, 2009).

\section{What to evaluate: the therapist's behaviors and the therapeutic relationship}

The therapist itself should be object (and subject) of the evaluation, being the main agent of the change stimulated by the treatment, and the active promoter of the therapeutic relationship (Baldwin \& Imel, 2013; Di Nuovo, 2011). Norcross \& Lambert (2019) and Norcross $\&$ Wampold (2019) have edited two volumes reporting the evidence-based findings on the therapist contributions and responsiveness. They show the specific therapists' behaviors improving treatment efficacy, and patients' characteristic to be assessed for tailoring effective psychotherapy: e.g., therapist's emotional expression and self-disclosure can adapt therapy to the patient's social identity and sexual orientation. Through a synthesis of the available research on clinical expertise and patient characteristics, an evidence-based reference for students and practitioners of psychotherapy is offered.

\section{What to evaluate: the common clinical practice}

A research with an ecological value studies what is commonly done in clinical practice, with patients not se- lected and without any alteration of the natural setting; differently from the laboratory model, in which treatments are targeted from the beginning to research objectives, the therapist follows a standard manual and the clients, pre-selected on the basis of particular characteristics, know that the therapy is also aimed at research purposes.

\section{What to evaluate: the single-cases studies}

Even single cases are frequent object of study in psychotherapy research: these studies can follow a rigorous methodology, well developed and affirmed (e.g., Kazdin 2010; Manolov, Gast, Perdices, \& Evans, 2014; McDonald et al., 2017; Yin, 2003), and use appropriate ad reliable data analysis techniques (Bauer, Lambert, \& Nielsen, 2004; Davidson \& Cheung, 2017; Jacobson \& Truax, 1991; Ogles, 2013). Some of these procedures are simple enough to be used by the therapists themselves.

The main challenges in single-cases research include participant adherence to within-person protocols, carryover and slow onset effects, suitability of behaviour change techniques for evaluation in N-of- 1 experimental studies, optimal allocation sequencing and blinding, calculating power/sample size, and choosing the most suitable analysis approach. Key solutions include involving users in study design, employing recent technologies for unobtrusive data collection and problem solving by design. Within-person designs share common methodological requirements with conventional between-person designs but require specific methodological considerations. (Kwasnicka et al., 2019, p. 163).

Based on a systematic review of 39 articles using single cases, both observational and interventional, to study or change health behaviours, McDonald et al. (2017) conclude that n-of- 1 methods provide the tools needed to help advance theoretical knowledge and personalise/tailor health behaviour interventions to individuals...The systematic review of n-of-1 studies in health behaviour research highlighted a number of unmet challenges and unanswered questions which should be considered in future research. While specifying an n-of- 1 protocol, investigators must make trade-offs between several factors including feasibility, measurement characteristics, scientific rigour and the specificity of the n-of-1 design. (pp. $307,318)$.

\section{When evaluate}

Not only before and after the treatment (and possibly at the follow-up) but also throughout the course of the therapy. Surely, the frequency of the assessment and the moments in which it is carried out affects the reliability of the results. Longitudinal research requires tools, methods and techniques for collecting and analyzing data different from the approach typical of laboratory experimentation (Kazdin, 2016). As regards data analysis of longitudinal single-case studies, Statistical analyses of 
n-of-1 data require accurate modelling of the outcome while accounting for its distribution, time-related trend and error structures (e.g., autocorrelation) as well as reporting readily usable contextualised effect sizes for decision-making (Vieira, McDonald, Araújo-Soares, Sniehotta, \& Henderson, 2017, p. 222).

\section{How to evaluate}

Many instruments, besides the psychometric tests, are available and can be used in the psychotherapy research: client's self-ratings, therapist's assessment sheets, check lists filled by participants or external observers. These tools can fit the researcher's theoretical model for verifying the effectiveness of the specific treatment or, being $a$ theoretical, can be shared by different models to allow the comparison of results. Following qualitative approaches (e.g., the narrative and conversational methods cited above), instruments can be aimed at reconstructing latent meaning structures (McLeod, 2011; Mörtl \& Gelo, 2015). The qualitative approach does not imply a simple report or narrative of experience: the logic of bricolage, introduced by Denzin and Lincoln in their qualitative research manual (Denzin \& Lincoln, 2017, $5^{\text {th }}$ ed.), compares the researcher to a craftsman who puts together and adapts the materials available to complete in the best way the specific product he works on. However, in order to proceed with a good qualitative research practice like highlevel bricolage, we need artisans specially trained on the procedures to be adopted and on their actual clinical relevance: otherwise some of these methodologies risk to transform the need to avoid an uncontrolled nomotheticity in an equally uncontrolled return to the subjectivity of the therapist's evaluations.

\section{How to generalize}

A relevant problem concerns the extension of the results (in the sense of cumulating data and articulating the models based on them) in order to assure the external validity and the generalizability of clinical research. Especially if the data are based on a few participants, or on individual cases, the interpretations can be drawn - instead of the usual statistical-probabilistic inference difficult when starting from small samples or single studies - rather on the extension of the applicability of methods and techniques to different clients, settings, and contexts. In this methodological approach is useful the meta-analysis, a cumulative strategy for analyzing the effects derived from a series of studies published on the same subject, and the factors involved in moderating the effects obtained (Borenstein, Hedges, Higgins, \& Rothstein, 2009; Cooper, Hedges, \& Valentine, 2009). Starting with the classic study by Smith, Glass and Miller (1980), meta-analysis has often been applied to psychotherapy studies. Also aggregated analyses of n-of-1 data are possible, e.g., using randomeffects or mixed models based meta-analysis (Araújo,
Julious, \& Senn, 2016). Summarizing the methods of design, analysis, and meta-analysis used in N-of-1 trials, Punja, Bukutu, Shamseer, Sampson, Hartling, Urichuk, \& Vohra (2016) conclude that, while most reports statistically analyzed single-case studies, only few meta-analyzed their results. It has been demonstrated that the inclusion of $\mathrm{N}$ of-1 trial data in the meta-analysis impacted both magnitude and precision; if the overall goal of a meta-analysis is to synthesize all available evidence on a given topic, then N-of-1 trials should be included (Punja, Schmid, Hartling, Urichuk, Nikles, \& Vohra, 2016).

The process of generalization and validation of the model through the extension of the different fields in which it can be reliably exported, is well exemplified by the research in which the effects are obtained and replicated in different contexts (for example, diverse institutions or organizations).

\section{Some proposals}

We need to leave wide space in public and private psychotherapy training schools to the presentation of the problems so far exposed. Both the knowledge of the results obtained making empirical research on psychotherapy, and the research training in the terms indicated above have to be implemented. This purpose should involve different approaches, not in an eclectic and undifferentiated assembling, but through the comparison and integration of results and methods in a superordinate model of taking care of the physical and mental health.

We should design multi-center and cumulative studies on specific topics of psychotherapy research, promoted by psychotherapy specialization schools, coordinated by scientific societies, within which to set up networks of research groups. We need studies conducted by adequately trained psychotherapists, in the logic of research-intervention and with the methods available and privileged in this approach of research. The data of these multi-centric studies could be analyzed cumulatively in search of shared meanings, with the aim of producing the ground for a scientific monitoring of the training and of the application of the skills formed, increasing the overall level of quality of psychotherapies practiced with different approaches and in different contexts.

\section{References}

Araújo, A., Julious, S., \& Senn, S. (2016). Understanding variation in sets of n-of-1 trials. PLoS One, 11(12), e0167167. doi: 10.1371/journal.pone.0167167.

Ardito, R. B., \& Rabellino, D. (2011). Therapeutic alliance and outcome of psychotherapy: historical excursus, measurements, and prospects for research. Frontiers in Psychology, 2, 270. doi: 10.3389/fpsyg.2011.00270.

Baldwin, S. A., \& Imel, Z. E. (2013) Therapist effects: Findings and methods. In M. J. Lambert (Ed.), Handbook of psy- 
chotherapy and behavior change. 6th ed. (pp. 258-296). New York: Wiley.

Bauer, S., Lambert, M. J., \& Nielsen, S. L. (2004). Clinical significance methods: a comparison of statistical techniques. Journal of Personality Assessment, 82(1), 60-70. doi: 10.1207/s15327752jpa8201_11.

Borenstein, M., Hedges, L. V., Higgins, J. P. T., \& Rothstein, H. (2009). Introduction to meta-analysis. Chichester: Wiley.

Castonguay, L. G., Nelson, D. L., Boutselis, M. A., Chiswick, N. R., Damer, D. D., Hemmelstein, ... Borkovec, T. D. (2010). Psychotherapists, researchers, or both? A qualitative analysis of psychotherapists' experiences in a practice research network. Psychotherapy: Theory, Research \& Practice, 47(3), 345-354. doi: 10.1037/a0021165.

Cooper, H., Hedges, L. V., \& Valentine, J. (Eds.) (2009). The handbook of research synthesis and meta-analysis. 2nd ed. New York: Russell Sage.

Davidson, K. W., \& Cheung, Y. K. (2017). Envisioning a future for precision health psychology: Innovative applied statistical approaches to N-of-1 studies. Health Psychology Review, 11(3), 292-294. doi: 10.1080/17437199.2017. 1347514.

Denzin, N. K., \& Lincoln, Y. S. (Eds.) (2017). Handbook of qualitative research. 5th ed. Thousand Oaks: Sage.

Di Nuovo, S. (2011). Speaking about therapists... Old questions and some answers derived from empirical evidence. Research in Psychotherapy, 14(2), 52-75. doi: 10.4081/ripppo.2011.22

Doidge, N. (2007). The brain that changes itself. New York: Penguin.

Elliott, R. (2000). Hermeneutic single case efficacy design. Paper presented at the 31st Annual Meeting of the Society for Psychotherapy Research, Chicago. Reprinted in Psychotherapy Research, 12(1), 1-22. doi: 10.1080/713869614. [It. tr. in Di Nuovo, S. Strumenti qualitativi per la ricerca sulla psicoterapia: l'intervista sul cambiamento terapeutico di R. Elliott. Ricerca in Psicoterapia, 3(2-3), 135-146].

Flückiger, C., Del Re, A. C., Wampold, B. E., Symonds, D., \& Horvath, A. O. (2012). How central is the alliance in psychotherapy? A multilevel longitudinal meta-analysis. Journal of Counseling Psychology, 59(1), 10-17. doi: 10.1037/ a0025749.

Gabbard, E. O. (Ed.) (2009). Textbook of psychotherapeutic treatments. Washington: American Psychiatric Publishing.

Gallagher, S., \& Zahavi, D. (2008). Phenomenological mind. London: Routledge.

Gelo, O. G. G., Salcuni, S., \& Colli, A. (2012). Text analysis within quantitative and qualitative psychotherapy process research: Introduction to special issue. Research in Psychotherapy: Psychopathology, Process and Outcome, 15(2), 45-53. doi: 10.7411/RP.2012.005.

Getz, K. A. \& Campo, R. A. (2017). Trial watch: Trends in clinical trial design complexity. Nature Reviews Drug Discovery, 16, 307. doi: 10.1038/nrd.2017.65.

Guthrie, E., \& Moorey, J. (2018). The theoretical basis of the Conversational Model of Therapy, Psychoanalytic Psychotherapy, 32(3), 282-300. doi: 10.1080/02668734.2018.1480055.

Hill, C. E., \& Knox, S. (2009). Processing the therapeutic relationship. Psychotherapy Research, 19(1), 13-29. doi: 10.1080/10503300802621206.

Hill, C. E., \& Knox, S. (2013). Training and supervision in psychotherapy, in M. J. Lambert (Ed.), Handbook of psychotherapy and behavior change. 6th ed. (pp. 775-810). New York: Wiley.
Hobson, R. (1985). Forms of feeling: The heart of psychotherapy. London: Tavistock Publications.

Jacobson, N. S., \& Truax, P. (1991). Clinical significance: A statistical approach to defining meaningful change in psychotherapy research, Journal of Consulting and Clinical Psychology, 59, 12-19. doi: 10.1037//0022-006x.59.1.12

Kandel, E. R., Schwartz, J. H., Jessell, T. M., Siegelbaum, S. A., \& Hudspeth, A. J. (Eds.) (2013). Principles of neural science, 5th ed. New York: McGraw-Hill.

Kazdin, A. E. (2010). Single-case research designs: Methods for clinical and applied settings. 2nd ed. New York: Oxford University Press:.

Kazdin, A. E. (2016). Research design in clinical psychology. 5th ed. New York: Pearson.

Korner, A., \& McLean, L. (2017). Conversational model psychotherapy. Australasian Psychiatry, 25(3), 219-221. doi: 10.1177/1039856216689649.

Kwasnicka, D., Inauen, J., Nieuwenboom, W., Nurmi, J., Schneider, A., Short, C. E.,...Naughton, F. (2019) Challenges and solutions for N-of-1 design studies in health psychology. Health Psychology Review, 13(2), 163-178. doi: 10.1080/17437199.2018.1564627.

Lambert, M. J. (Ed.) (2013). Handbook of psychotherapy and behavior change. 6th ed. New York: Wiley.

Lane, D. A., \& Corrie, S. (2006). The modern scientist-practitioner. A guide to practice in psychology. London: Routledge.

Le Doux, J. (2000). Synaptic Self: How our brains become who we are. New York: Wiking.

Lutz, W., \& Knox, S. (Eds.) (2013). Quantitative and qualitative methods in psychotherapy research. London: Routledge.

Manolov, R., Gast, D. L., Perdices, M., \& Evans, J. J. (2014). Single-case experimental designs: Reflections on conduct and analysis. Neuropsychological Rehabilitation, 24(3), 634-660. doi: 10.1080/09602011.2014.903199.

Martin, D., Garske, J., \& Davis, K., (2000). Relation of therapeutic alliance with outcome and others variables: A metaanalytic review. Journal of Consulting and Clinical Psychology, 68, 438-450. doi: 10.1037/0022-006X.68.3.438

McDonald, S., Quinn, F., Vieira, R., O’Brien, N., White, M., Johnston, D. W., \& Sniehotta, F. F. (2017). The state of the art and future opportunities for using longitudinal n-of-1 methods in health behaviour research: A systematic literature overview. Health Psychology Review, 11(4), 307-323. doi: 10.1080/17437199.2017.1316672.

McLeod, J. (2011). Qualitative research in counselling and psychotherapy. 2nd ed. London: Sage.

Meares, R. (2004). The conversational model: an outline. American Journal of Psychotherapy, 58(1), 51-66. doi: 10.1176/appi.psychotherapy.2004.58.1.51.

Meares, R. (2012). Borderline personality disorder and the conversational model: A clinician's manual. New York: Norton.

Molenaar, P. C. M., \& Campbell, C. G. (2009). The new personspecific paradigm in psychology. Current Directions in Psychological Science, 18(2), 112-117. doi: 10.1111/j. 14678721.2009.01619.x

Mörtl, K., \& Gelo, O. C. G. (2015). Qualitative methods in psychotherapy process research. In O. Gelo, A. Pritz, B. Rieken (Eds.), Psychotherapy Research (pp. 381-428). Wien: Springer.

Norcross, J. C., \& Lambert, B. E. (Eds.) (2019). Psychotherapy relationships that work. Vol. 1: Evidence-based therapist contributions. 3rd ed. Oxford: Oxford University Press. 
Norcross, J. C., \& Wampold, B. E. (2011). What works for whom: Tailoring psychotherapy to the person. Journal of Clinical Psychology, 67(2), 127-132. doi: 10.1002/jclp.20764.

Norcross, J. C., \& Wampold, B. E. (Eds.) (2019). Psychotherapy relationships that work. Vol. 2: Evidence-Based therapist responsiveness. 3rd ed. Oxford: Oxford University Press.

Ogles, B. J. (2013). Measuring change in psychotherapy research. In M. J. Lambert (Ed.), Handbook of psychotherapy and behavior change. 6th ed. (pp. 134-166). New York: Wiley.

Peräkylä, A., Antaki, C., Vehviläinen, S., \& Leudar, I. (Eds.) (2008). Conversation analysis and psychotherapy. Cambridge: University Press.

Price, P. B., \& Jones, E. E. (1998). Examining the alliance using the Psychotherapy Process Q-Set. Psychotherapy: Theory, Research, Practice, Training. 35(3), 392-404. doi: 10.1037/h0087654.

Punja, S., Bukutu, C., Shamseer, L., Sampson, M., Hartling, L., \& Urichuk, L. (2016). N-of-1 trials are a tapestry of heterogeneity. Journal of Clinical Epidemiology, 76, 47-56. doi: 10.1016/j.jclinepi.2016.03.023.

Punja, S., Schmid, C. H., Hartling, L., Urichuk, L., Nikles, C.
J., \& Vohra, S. (2016). To meta-analyze or not to meta-analyze? A combined meta-analysis of N-of-1 trial data with RCT data on amphetamines and methylphenidate for pediatric ADHD. Journal of Clinical Epidemiology 76, 76-81. doi: 10.1016/j.jclinepi.2016.03.021.

Rennie, D. L. (2012). Qualitative research as methodical hermeneutics. Psychological Methods, 17(3),385-398. doi: 10.1037/a0029250.

Smith, M. L., Glass, G. V., \& Miller, T. I. (1980). The benefits of psychotherapy. Baltimore: John Hopkins University Press.

Vieira, R., McDonald, S., Araújo-Soares, V., Sniehotta, F. F., \& Henderson, R. (2017). Dynamic modelling of n-of-1 data: powerful and flexible data analytics applied to individualised studies. Health Psychology Review, 11(3), 222-234. doi: 10.1080/17437199.2017.1343680.

Wampold, B. E., \& Imel, Z. E. (2015). The great psychotherapy debate: the evidence for what makes psychotherapy work. 2nd ed. New York: Routledge.

Yin, R. K. (2003). Case study research, design and methods. 3rd ed. Newbury Park: Sage. 